\title{
Serving Generation 1.5 Learners in the University Writing Center
}

\author{
Terese Thonus
}

Second-language writers attending U.S. colleges and universities generally fall into one of three groups:

1. EFL writers who were educated in their mother tongue (L1) and are learning English as their L2 (often referred to as foreign or international students)

2. ESL writers who are recent immigrants to the United States, often with educational backgrounds in their L1

3. Generation 1.5 writers who are long-term U.S. residents and English learners fluent in spoken English.

Harklau, Losey, and Siegal (1999), in their book, titled Generation 1.5 Meets College Composition: Issues in the Teaching of Writing to U.S.-Educated Learners of English, describe the third group as follows:

With backgrounds in U.S. culture and schooling, they [Generation 1.5 writers] are distinct from international students or other newcomers who have been the subject of most ESL writing literature, while at the same time these students' status as English language learners is often treated as incidental or even misconstrued as underpreparation in writings on mainstream college composition and basic writing. (p. vii)

In fact, because they have come up through the public school system, where mainstreaming (actually submersion) and age-related promotion have obscured their status as English language learners, Generation 1.5 writers themselves eschew the label ESL. As a result, they have largely been ignored by writing specialists who study native speakers of English because their writing contains nonnative, ESL features. Likewise, they also have been ignored by writing specialists who study nonnative speakers of English because they rarely enroll in ESL writing classes.

In this article, ${ }^{1}$ I explain how a key academic support service, the university writing center, can assist Generation 1.5 students as they develop their writing skills. Because of its autonomous status within the university, the writing center offers an opportunity for Generation 1.5 students (who may not want to refer to themselves as ESL students) to receive L2 writing instruction in an anonymous and unstigmatized atmosphere. By recognizing the learning abilities and limitations that distinguish Generation 1.5 students from other ESL learners, writing tutors and, by extension, writing instructors can develop appropriate intervention strategies for this growing segment of the U.S. postsecondary population. Furthermore, the principles and practices highlighted in this article may be applied during writing conferences and other teacher-student exchanges intended to improve students' L2 writing ability.

Writing centers in U.S. colleges and universities began as writing labs in the 1930s. Lab clients were racial, ethnic, or gender minorities judged by their teachers to need remediation. This characterization of writing centers as places where these students' special needs are met by the university has changed as the centers have become mechanisms for increasing access to and retaining students. Today, they play a vital role in freshman writing programs

A proposal for serving Generation 1.5 students in the writing center must begin with an awareness of the similarities and differences in the backgrounds and needs of Generation 1.5 and ESL/EFL writers.

as well as provide support to more advanced students in writing across the disciplines. Typically, writing centers offer one-on-one tutoring to students who self-identify as needing assistance with course assignments and research papers.

Writing center pedagogy assumes that students can (a) verbalize what they want to write, (b) express themselves clearly and correctly in English, (c) reply to questions about writing, (d) perceive what sounds right on paper, and (e) focus on and value organization and development more than sentence-level correctness. Tutors are to employ a Socratic approach when questioning, polite indirection when suggesting, and other tutorial practices (e.g., jogging the student's memory) that tend to be ineffective with L2 writers (Plummer \& Thonus, 1999; Thonus, 1999). Recently, however, the proposal of new methodologies in conference presentations and at workshops suggests that researchers who study writing tutorials and native-Englishspeaker (NS) composition have rediscovered L2 writers. Although these are steps in the right direction, updated methods still respond primarily to the needs of ESL/EFL writers and not the needs that are more distinctly characteristic of the Generation 1.5 group.

A proposal for serving Generation 1.5 students in the writing center must begin with an awareness of the similarities and differences in the backgrounds and needs of 
Generation 1.5 and ESL/EFL writers. First, it is important for writing center personnel and teachers who want to promote nonnative-English-speaking (NNS) students' writing skills to understand the similarities among the three groups of students, many of whom

- want tutors who can reflect the university's academic audience yet display cultural sensitivity, encouraging the writer's authentic voice

- need assistance with reducing the cognitive load of L2 writing

- lack native-like intuitions about what sounds right on paper, in that writing is auxiliary to language acquisition

- need extensive vocabulary development and help with pronunciation

- require instruction in using self-access resources, such as writer's handbooks, learner dictionaries, thesauruses, and grammar texts

- struggle with sentence-level problems of syntax and punctuation

- prefer explicit direction from tutors, in contrast to the polite indirectness favored by NS tutees (Gilewicz \& Thonus, 2000; Thonus, 1999).

Second, it is essential to recognize certain key differences between Generation 1.5 and other college-level writers. Generation 1.5 students

- face different socioeconomic and sociocultural realities. According to Harklau et al. (1999), they are often the first in their families to accomplish at least one of the following: (a) become literate in any language, (b) complete high school, (c) attend college. In contrast, many ESL/EFL learners studying at U.S. universities (and their parents) have had access to literacy and education in their countries of origin.

- have experienced marginalization in their elementary and secondary educations because of their perceived minority status. They may have been assigned to English language development and remedial classes and relegated to noncollege preparatory coursework. They may even have been steered toward vocational and community college postsecondary options. In contrast, other EFL/ESL writers may have been high-performing students in their countries of origin and esteemed by the community for their desire to further their educations in the United States.

- are primarily ear learners, whereas ESL/EFL writers are primarily eye learners. As a result, Generation 1.5 writers may possess more of an intuitive sense of what sounds right than other L2 writers, who, when monitoring their writing, tend to appeal to rules. Although their oral language is generally more fluent and their pronunciation more NS-like than that of other L2 writers, Generation 1.5 writers may have more difficulty distinguishing between oral and written varieties of English.

- are familiar with the process approach in English composition through their experience in U.S. schools, whereas ESL/EFL writers may be unaware of the concepts of brainstorming, drafting, revising, and editing.

- have participated in one-on-one writing conferences with instructors, whereas ESL/EFL writers often have not. In class and in these conferences, Generation 1.5 students have had some exposure to the rhetorical patterns and metalanguage of academic English; nonetheless, they may not yet control this language themselves.

Because of the lack of maintenance bilingual education and the push toward cultural assimilation, these U.S.educated students have lost, or are in the process of losing, their home language(s) without having learned their writing systems or academic registers. Thus, unlike international students and adult immigrant learners, Generation 1.5 writers may lack a basis of comparison in fully developed oral, written, or both systems of a first language. On the other hand, they are more familiar with U.S. academic writing practices and teacher and institutional expectations of student performance than their ESL/EFL peers.

\section{Pedagogical Practices}

A number of pedagogical practices are well suited for facilitating Generation 1.5 student learning in the writing center. The following five general principles may be applied to tutoring these learners. Each principle is accompanied by transcribed excerpts from tutor-student conversations and interview data collected at two U.S. university writing centers. ${ }^{2}$ The first of the excerpts in each case displays less than exemplary practices; the second illustrates tutorial practices that are more successful with Generation 1.5 writers and, in some cases, with all L2 writers. (For a description and key of the transcription conventions used in the excerpts, see the Appendix.)

\section{Teach the Metalanguage and Sociopragmatic Conventions of Writing}

Many writers come to the tutorial table with neither the specialized language to talk about writing (metalanguage) nor an understanding of the roles and responsibilities the tutor and tutee must assume (sociopragmatic conventions) for tutorials to be successful. I found (Thonus, 1998) that NNS tutees appreciated tutors' explanations of what to expect during the course of a tutorial; they also valued tutors who taught them how to write, not simply how to get through a particular assignment. Unfortunately, not all tutors possess this skill. Excerpt 1A illustrates an interaction between a Generation 1.5 student $(\mathrm{S})$ and a tutor $(\mathrm{T})$ who taught her neither the sociopragmatic conventions of tutorials nor how to discuss writing. 


\section{Excerpt $1 \mathrm{~A}$}

T: O.K. So what you're trying to say here but you haven't said it yet is that socialization is really just a form of education?

S: $\quad$ uh-huh

(.) Um no.

T: It's not?

S: $\quad$ So

T: $\quad$ So there's no relationship between socialization and [education.

S: $\quad$ [So, so I have to write the reason for this one, just write. Because they use different, different ways to teach

children. [They have, girls should be like this and boys should be like this. So that's a [uh-huh

different kind of teaching instruction, [educational instruction, so that's kind of [o.k.

socialization. Yeah, so should I just write like this one?

Yeah, I think so. [I mean, it's, it's, yeah, write, write, take their evidence and show how

S:

T: (.) it's (.)

S: Related?

T: Yeah, how it's related to (.) you know

S: $\quad$ Education?

T: That this is done through education and instruction. S:

T: and then, next paragraph, S:

$\mathrm{T}$ : having a thesis statement ...

uh-huh, o.k. Yeah, that's precisely,

At the end of the tutorial ("unfortunately, we're out of time for today"), $T$ admonishes $S$ ("you need to be working on sort of the larger issues right now"), in spite of the fact that he has talked only about the particulars of the relationship between ideas in S's paper rather than any larger issues in writing instruction. This is the only time in the tutorial that T mentions the term thesis statement, which a later interview with $S$ confirmed was a metalinguistic term employed by her course instructor and classmates, one she longed to use herself and that her tutor might have explained to her.

The tutor in Excerpt 1B does a better job of explaining to a Generation 1.5 writer what he can reasonably expect from the tutorial.

\section{Excerpt 1B}

T: Have you been to the writing center before for tutoring?

S: $\quad$ No.

T: We don't really do corrections of grammar and [sentence-level. We can talk about

S:

$\mathrm{T}:$

S:

$\mathrm{T}:$

S:

$\mathrm{T}:$

S:

$\mathrm{T}:$ S: [You don't?

the grammar issues [and definitely we can help you with your concerns. [yeah

o.k.

But um I don't, I don't fix what's wrong.

((laugh)) You're not supposed to?

No, [no.

Because the philosophy behind that is, if I do it for

[o.k.

you, you're never going to, to figure out how to do it for your[self.

me how to [fish, then?

[So you want um teach 
$\mathrm{T}: \quad[\mathrm{Ex}-$

Exactly. [Teach a person to fish and they'll eat for their

lifetime, is that how it [goes?

$[(($ laugh $))$

T:

S:

[*** giving me a fish. (.)

I'm not going to give you [a fish. O.K. [((laugh))

[o.k. $\quad[($ laugh $))$

To clarify the purpose of the tutorial by spelling out the rules ("We don't really do corrections of grammar and sentencelevel. . . I don't fix what's wrong"), T tells $S$ that instead of "giving him a fish" she seeks to "teach [him] to fish." Notice that the student himself anticipates the alternative ("So you want um teach me how to fish, then?"). By explicitly teaching the tutorial conversation and the metalanguage of writing, tutors can empower writers to become full members of the academic discourse community.

\section{Affirm the Student's Cultural and Linguistic Heritage}

Although Generation 1.5 writers are longtime U.S. residents or citizens, their cultural and linguistic heritage may continue to impact their identity and self-esteem. Unfortunately, these affiliations are not always accepted and are often actively ignored by tutors and fellow students, as in the following excerpt of a group tutorial, where T and a NS tutee (S2) insist that Generation 1.5 writer $S 1$ use the term Cambodian rather than Khmer.

\section{Excerpt $2 \mathrm{~A}$}

T: O.K. ((to S3)) How do you say that?

S1: Khmer.

T: $\quad(($ to S2)) Thank you.

S2: Huh? (.) Khmer?

S1: Khmer.

S2: Khmer.

T: Um

S2: $\quad$ Khmer

S1: Well, English, use it, Khmer.

S2: That's English, or [no?

S1: $\quad$ [It's, it is in English, but um

S2: What does it mean? What is it?

S1: This one and Cambodian (2s) is the same thing, but um I guess it's easier for people to say "Cambodian" instead of "Khmer." All right, I'll put "Cambodian" in. ((laugh))

T: $\quad$ No.

S2: [No. We di-, I didn't know what it was.

T: Well just, as long as you explain in your paper what that is, you're fine.

S1: Oh, O.K. [I'll put, put "Cambodian." So. Right.

T: $\quad$ [So, yeah.

Although in the end T encourages S1 to use Khmer if he glosses it as Cambodian, S1 decides to use the latter label instead ("I'll put 'Cambodian' in"). T's acceptance of this decision aligns her with the other students rather than with S1, who needs her support.

Tutors can also show insensitivity to Generation 1.5 writers by marginalizing them in the tutorial conversation; even though the writers' speech is fluent, they may still be perceived as being foreign, so their contributions are often questioned or ignored. In one-on-one tutorials, they are given less time on the floor, and in group tutorials, they are often referred to in the third person rather than spoken to directly by other participants (Gilewicz \& Thonus, 2000). In Excerpt 2B, the Generation 1.5 student $(\mathrm{S} 1)$ is included and treated as a valuable member of the group.

\section{Excerpt 2B}

T: I think that $S 1$ was touching something good. ((to S1)) If that's his [S2's] thesis, what does he need to do with the rest of the paper? (3s)

S1: Should, I don't know. (2s)

T: And if we lose track of that being his thesis, then how do we fix that?

S1: ((to S2)) Kind of tie it in, in the conclusion? 
T: Yeah, that's definitely one way, and probably something that [um

S2:

the conclusion?

[So tie in my thesis into

S1: Yeah, you should, always.

T affirms S1's contribution to the discussion of S2's paper ("I think that S1 was touching something good"). In fact, T persists in soliciting S1's input despite S1's initial hesitation ("I don't know"). T then encourages S1 to engage S2 directly, which S1 does ("Kind of tie it in, in the conclusion?"). Although S1 struggles with written English, he is treated like any other group member and held accountable for his own progress. This acceptance and challenge are critical for the Generation 1.5 student's integration into the group and subsequent development as a writer.

\section{Balance Grammar Corrections With Rhetorical Concerns}

Tutors of all L2 writers are tempted to focus on sentence-level errors, even errors that do not impede comprehension, while setting aside rhetorical concerns. Because Generation 1.5 students' writing may manifest better organization and development than that of other L2 writers, the temptation for tutors to correct grammar is even greater. Note the experience of this tutor, who insists that "I received a Master's degree there in 1986" is more idiomatic than what the student wrote, "I received a Master's degree in 1986 there."

\section{Excerpt $3 \mathrm{~A}$}

T: “A (.) Master's (.) degree,” that's a possessive, uh-huh

S:

"there" should go um here, ["I received a Master's degree there in 1986." Um

“in 1986," and this word

S:

you, what's the difference between?

$$
\text { [uh-huh What }
$$

T: It's just it's a sort of word order um thing. This isn't incorrect, it's just stylistically a

S:

little strange because you have the time at the end uh-huh

of the sentence, right,

T: "in 1986," and so it's good to have the place [right next to that um because

S: hmm o.k. [o.k.

T: the subject of the sentence is "I," so you can start it with that.

What complicates T's correction in this excerpt is her inability to explain the rule behind it ("This isn't incorrect, it's just stylistically a little strange"). T is imposing her NS intuitions upon S's text rather than teaching him how to develop editing strategies that work.

In contrast, in Excerpt 3B, T refuses to focus on sentence-level errors until she has dealt with a larger concern, paragraph development. Despite T's efforts, though, S eventually steers her toward grammar correction.

\section{Excerpt 3B}

T: I found your writing really, really interesting, [and really descriptive.

S:

Thanks $[(($ laugh $))$

[oh, yeah? o.k.

$\mathrm{T}:$

the little details, and that, [that, that will help (.) help you finish up your

S:

T: $\quad$ autobiography.

S: [What about terms of grammar, you know? (.)

$\mathrm{T}$ : In terms of grammar, there were a few stylistic, there were a few

S:

T: Not really.

S: No?

T: No, if we read this aloud together (.) I, I bet that, I bet that there would be very few errors that we would hear.

Insisting that there is very little to correct, $T$ suggests they read the paper aloud together, an appropriate strategy for this U.S.-educated ear learner ("I bet that there would be very few errors that we would hear"). 


\section{Offer Explicit Direction}

Writing tutors are trained to offer indirect suggestions rather than explicit directives for the writer's revision (Thonus 1998, 1999), a practice exemplified by $\mathrm{T}$ in Excerpt $4 \mathrm{~A}$.

Excerpt $4 \mathrm{~A}$

T: O.K. That's the type of conclusion that you wrote originally?

This type of

T: conclusion is what you thought of originally?

um

Uh-huh.

T: O.K. Um, how do you feel about that now? Do you, do you still want to include some elements of the summary with your new [direction here or?

S:

Yeah, I think.

[Yeah.

T: O.K. How do you want to do that?

S: Um let me see...

As an alternative question missing its second conjunct, T's recommendation ("Do you still want to include some elements of the summary with your new direction here or?") provide $S$ with very little guidance, a tutoring practice encouraged with NS writers but of little help with L2 writers (Plummer \& Thonus, 1999). The transcript shows that $S$ is not only unable to articulate his intentions but also unable to write a summary-type conclusion on his own.

Contrast this indirect recommendation with the same tutor's direct instructions to another Generation 1.5 student, instructions that the transcript suggests helped the writer.

\section{Excerpt 4B}

T: What else do you do to the data besides just collect it?

S: $\quad$ Analyze [it.

T: $\quad[$ O.K. that's right. So there are two relationships that you have to this data. You collect it and you analyze it. Right? And so I think that would need, and that both of these help you answer the question that this study poses. This is not

S: $\quad$ uh-huh uh-huh

T: said. You leap straight from saying or suggesting that you're going to collect it,

S: uh-huh and there isn't a sense of what status or function or purpose your

T: collecting the data might have. And in fact, secondly, you don't mention that you're analyzing it. So I think this is what needs to get said here in this sentence.

Whereas T's critiques ("This is not said. You leap straight from saying or suggesting that you're going to collect it") and directives ("this is what needs to get said here in this sentence") might not be welcomed by a NS student, research suggests that many English learners prefer explicit direction rather than oblique suggestions (Thonus, 1999). In this case, rather than keeping $S$ guessing at answers to questions he may neither understand nor have the ability to answer, $T$ takes on the role of a writing instructor - a role proscribed by writing center administrators and teachers but often beneficial to the L2 writer.

\section{Avoid Appealing to (NS) Intuitions}

One corollary to the previous principle on offering explicit direction is to avoid questions that imply that the student, because of his or her oral proficiency in English, should know a word or language rule. Tutor questions that put the student on the spot are ineffectual, as Excerpt 5A shows.

\section{Excerpt $5 \mathrm{~A}$}

T: Doesn't this (.) sentence address important or pervasive findings?

S: Yeah.

$\mathrm{T}$ : Is this finding important to you?

S: Yeah, I think so, yeah.

T: O.K., well then. How about "pervasive"? (.)

S: Pervas-, what does "pervasive" mean?

$\mathrm{T}$ : What do you think it means? 
S: Huh?

T: What do you think it means?

S: Yeah.

T: No, what do you think it means?

S: Um (7s) Well, it's similar to "important."

T: Actually, no. [It means um very frequent. [Almost dominant.

S:

\author{
[No? [Frequent.
}

T suggests a vocabulary word ("How about 'pervasive'?"). Then, despite S's query as to the meaning of the term ("What does 'pervasive' mean?"), he asks her three times what she thinks it means. When $S$ hazards an answer ("Well, it's similar to "important"), $T$ tells her that she is wrong and defines it himself. By the end of the interchange, $T$ is frustrated and $S$ is embarrassed-hardly emotions conducive to learning.

In Excerpt 5B, T recognizes the Generation 1.5 student's strengths and limitations; she asks questions that $S$ can actually answer given sufficient time.

\title{
Excerpt 5B
}

T: O.K. O.K, there were a couple of, let me look over this for just grammatical things. I think

there was something I saw that I wasn't, wasn't clear about (38s) O.K. Here, it's this sentence.

"The second part of this lab that was done is called the Hill reaction." Um this part, well,

this first little bit, "the second part of this lab that was done is called," seems sort of wordy.

I'm not sure if, if there would be some other way you could say that.

S: "The Hill reaction was the second part of this lab?"

T: I think that's a good idea. [((laugh)) So was the second part, yeah. (.) Because you

S:

T: tend to sort of get lost in the prepositional phrases and things here and I wasn't sure.

"Was the second part of this lab." (.) Yeah.

S: But then again, you know, you think he's saying that he, like, that he gets maybe to a person that doesn't know what the Hill reaction is [or whatever, it's like...

$\mathrm{T}:$

doing, explaining down here?

[Well, is that, isn't that what you're

S: $\quad$ o.k

Yeah, that's true. Then should I go on to say, "The Hill reaction is done in order to test"? Yeah.

T: Well, I think saying it makes it clear that you're referring back to the Hill reaction, so I don't

think you need to repeat it. It makes sense to me.

T prompts $S$ with "I'm not sure if, if there would be some other way you could say that," and by permitting him to orally rehearse several options, she opens the way for him to refine his first self-suggestion: "Then should I go on to say, "The Hill reaction is done in order to test'?"

\section{Conclusion}

As the preceding excerpts from individual and group writing tutorials show, when Generation 1.5 learners interact with writing tutors trained in using methods that effectively respond to their needs, there is a greater chance they will improve their writing ability. By focusing learners' attention on how to write rather than what to write for a particular assignment, by emphasizing a balance between correct grammar usage and sound rhetorical style, and by offering learners explicit direction, writing center personnel, as well as ESL writing instructors in a variety of contexts, can foster the writing ability of Generation 1.5 and other L2 students.

\section{Notes}

${ }^{1}$ This article is a revised version of "Retooling the Writing Center for L2 Writers of Diverse Backgrounds," presented as part of the InterSection panel, Teacher Education/ESL in
Higher Education, at the 35th Annual TESOL Convention (2001), in St. Louis, Missouri, in the United States.

${ }^{2}$ Tutorial excerpts are drawn from individual tutorials in writing across the disciplines, Indiana University, Bloomington, and group tutorials for basic and freshman composition students, California State University, Fresno.

\section{References}

Bardovi-Harlig, K., \& Hartford, B. S. (1993). Learning the rules of academic talk: A longitudinal study of pragmatic change. Studies in Second Language Acquisition, 15, 279-304.

Edwards, J. A. (1993). Principles and contrasting systems of discourse transcription. In J. A. Edwards \& M. D. Lampert (Eds.), Talking data: Transcription and coding in discourse research (pp. 1-31). Hillsdale, NJ: Erlbaum.

Gilewicz, M., \& Thonus, T. (2000, November). Descriptive and evaluative language in group tutorials. Paper presented at the National Writing Centers Association, Baltimore, MD.

Harklau, L., Losey, K. M., \& Siegal, M. (Eds.). (1999). Generation 1.5 meets college composition: Issues in the teaching of 
writing to U.S.-educated learners of English. Mahwah, NJ: Erlbaum.

He, A. W. (1998). Reconstructing institutions: Language use in academic counseling encounters. Greenwich, CT: Ablex.

Plummer, L., \& Thonus, T. (1999, April). Methodology as mythology: Tutors' directive instruction. Paper presented at the National Writing Centers Association, Bloomington, IN.

Thonus, T. (1998). What makes a writing tutorial successful: An analysis of linguistic variables and social context. Unpublished doctoral dissertation, Indiana University, Bloomington.

Thonus, T. (1999). How to communicate politely and be a tutor, too: NS-NNS interaction and writing center practice. Text, $19,253-279$.

\section{Author}

Terese Thonus is assistant professor of linguistics at California State University, Fresno, in the United States, where she teaches courses in TESL and applied linguistics. Her research interests include oral discourse analysis, teacher and tutor education, and writing. She has published in numerous journals, including The Writing Center Journal, Discourse \& Society, Text, American Speech, and World Englishes.

Appendix: Transcription Conventions

The transcription conventions used in the tutorial excerpts in this article are those employed by Edwards (1993), in which a vertical, running arrangement of text incorporates utterance and nonutterance materials in real time (i.e., several speakers' lines are presented simultaneously). Additional symbols were culled from Bardovi-Harlig and Hartford (1993) and He (1998).

Utterance (linguistic) material is represented by conventional U.S. English spellings for words and parts of words. Filled pauses (e.g., um, hmm) and listener responses (e.g., Uh-huh, O.K., Huh.) are represented and treated as words. Conventional punctuation (e.g., periods, commas, question marks) signals basic intonation contours (e.g., statements with falling intonation; interrogatives with rising or falling intonation, or both, depending on the type). Emphatic statements are marked by exclamation points. Overlaps between participant contributions are marked using brackets aligned directly above one another. Overlaps continue until one interlocutor completes his or her utterance. Then, one participant takes the floor again on a new line.

Example

S: $\quad$ Should I add that, maybe?

T: O.K. But then so $\mathrm{b}$ and $\mathrm{c}$, so then you say, or the legs, you're saying that $\mathrm{c}$ is two things. It's both the legs of the triangle [and the hypotenuse.

T: Ah, O.K. ((laugh)) I was thinking, I don't remember that, but it seems so wrong!

Consistent with a vertically arranged transcript, multiple overlaps are sequenced spatially:

T: Yes, yeah. (6s) You tend to use of um words like "incredibly"

S:

$\mathrm{T}:$

\section{"Amazingly"}

"amazingly" and "strangely" and stuff like that.

And

Backchannel cues, feedback in the form of verbal signals given by one participant while another is speaking, are inserted on the line just below the speaker's (e.g., S's utterance of "uh-huh") in the following example:

T: But the point is, I'm a reader who has not read the essay.

S:

T: you're, I have, I know what your argument is here.

I know what

uh-huh

\section{uh-huh}

I don't feel, as a reader,

T: I don't feel that your, your paragraph there is any better, has any more substance to it (.) with that quote in it

S: $\quad$ uh-huh

Backchannel cues appear in lowercase form (e.g., "o.k.") to distinguish them from listener responses (“O.K.”), as in T's utterances in the first excerpt above. Nonutterance (e.g., nonlinguistic, paralinguistic) material is coded using the following conventions:

Key to Codes for Nonutterance Material

(.) Short pause (1-2 seconds)

(5s) Timed pause (2 or more seconds)

(( )) Additional observation: laugh, cough, sigh

*** Doubtful hearing 